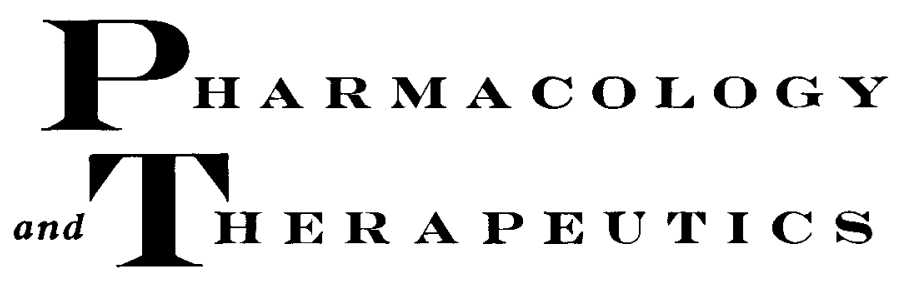

volume 11 number 4

July-August, 1970

\title{
Commentary
}

\section{A short course in clinical pharmacology}

Edward A. Carr, Jr., M.D. Ann Arbor, Mich.

Departments of Internal Medicine and Pharmacology, and the Upjohn Center for

Clinical Pharmacology, University of Michigan

The public, its representatives in government, and its practicing physicians have a well-known and well-documented interest in the opportunities and problems created by changes in drug therapy during the past twenty-five years. Their interest does not require further documentation here. The topic of the present report is the response of academe to these opportunities, problems, and widespread interest.

The most reliable list of American schools of medicine that have initiated programs in clinical pharmacology is, to my knowledge, the tabulation entitled Clinical Pharmacology Training Programs, made available in 1968 by the American Society for Pharmacology and Experimental Therapeutics. It is possible that a few medical schools with active training programs in clinical pharmacology were overlooked for some reason when this list was drawn up, and the present report casts no disparagement on such schools, if they exist. But there is little doubt that the list is quantitatively the most reliable source available to anyone wishing to conduct a poll among clinical pharmacology groups in American schools at the present time. Therefore, in the Spring of 1969, I sent the following request for information to the director of each of the listed programs:

"As Director of Clinical Pharmacology at your Medical School, you are in a better position to know the status of teaching of clinical pharmacology and therapeutics to medical students than any other individual working there. The Editorial Board of Clinical Pharmacology and TheraPEUTics has asked me to write a brief commentary on the current status of teaching in this area; I would greatly appreciate your filling out the two lines at the bottom of this page and returning the answer to me in the enclosed envelope. I have tried to make this as brief as possible, and I 
hope you will send me your reply by return mail."

In further explanation of the question the following instruction was included:

"The question here refers to medical students in all of the four years of medical school, but only to medical students. For simplicity, the hour is taken as the unit of teaching. A session is considered devoted to clinical pharmacology or therapeutics if it is primarily devoted to these subjects, even if a small amount of the time covers some other material. On the other hand, the usual pharmacology lecture or the usual diagnostically oriented medical staff conference or ward round presentation is not considered clinical pharmacology and therapeutics in this context, even if a small amount of clinical pharmacology and therapeutics material is considered. The question concerns all teaching of clinical pharmacology and therapeutics, however, whether done by you and your group or by others in the medical center.

1. Accepting these admittedly rough definitions, how many hours of teaching in clinical pharmacology and therapeutics does the average medical student receive during the entire four years at your school? hours.

2. Please indicate whether you consider this to be a precise figure___ fairly precise estimate___ only a rough estimate

There are 35 programs on the list. Response was obtained from 32 directors (including my own response for the program at the University of Michigan). Thus, the over-all response rate was 91 per cent. I submit that the data so obtained, though admittedly concise to the point of extreme simplicity, represent at least one piece of significant information regarding the teaching of clinical pharmacology and therapeutics in American schools of medicine one-quarter century after the close of World War II initiated a period of pharmacologic expansion without parallel in history.

According to the reports received, the average medical student receives during his entire four years a mean of 31 hours of instruction in clinical pharmacology and therapeutics, the range being 0 to 100 hours. The median is 22 hours. If these reports are representative of the situation throughout the United States, the teaching of clinical pharmacology and therapeutics in most schools of medicine in our country is an academic laugh-in. Most medical students receive fewer hours of teaching in clinical pharmacology and therapeutics than they receive in any subsub-specialty, elective, or private project to which they are assigned for 3 full days during their entire four years of medical school. The course in clinical pharmacology is a very short course indeed!

It is first prudent to consider whether matters are really as bad as they seem. There are four possible bases for denying that the situation is all that serious: The schools polled may not be representative of all American medical schools; the individuals responding may have underestimated the amount of information about clinical use of drugs that is given to students in their respective schools; the "drug explosion" may be more cliche than fact, thereby rendering it unnecessary to give much instruction in the clinical use of drugs; or, finally, students may learn a great deal about subjects that are not presented during any formal hours of instruction, and the counting of such formal hours may therefore be irrelevant. I shall discuss these possibilities in the order presented.

It is certainly possible that the respondents, representing roughly one third of the American medical schools, are not representative of the entire picture in this country. In fact, it is very likely that they are not representative. For the other two thirds of the schools are probably in even worse condition! Although it is conceivable that schools having training programs in clinical pharmacology may use them as a form of tokenism and may thereby be less interested in the teaching of clinical pharmacology than 
other schools, this possibility seems to me remote and the suggestion appears to depend on a rather twisted argument. We live in an era in which the teaching of advanced students, such as the selected physicians who participate in most postgraduate training programs in clinical pharmacology, has acquired considerable prestige; schools that do not conduct such programs for advanced trainees are probably neglecting the teaching of clinical pharmacology to their medical students even more than schools that do have such training programs. Individual exceptions very probably exist and merit applause wherever they may be found. But the overwhelming probability is that schools which have not seen fit to initiate training programs in clinical pharmacology give even less instruction to medical students in the clinical use of drugs than those schools represented in the present survey,

The possibility of inaccuracy in the response merits more serious consideration. Twelve of the respondents stated that their figures were "only a rough estimate," 13 felt that they gave a "fairly precise estimate," and only 7 flatly stated that they were giving a "precise figure." Moreover, as one respondent pointed out, the request that time devoted to teaching of "therapeutics" be added to that devoted to "clinical pharmacology" makes it more difficult to give a really precise estimate. But clinical pharmacologists still form a sufficiently small circle to permit most of those engaged in the work to know almost everyone else in the field. Most of the respondents are personally known to me; they are careful and conscientious men who are intensely interested in this area. They are also in a better position to give an answer to the question asked than anyone else in their schools. Therefore, although the data are subject to the softness inherent in any data furnished by a single individual for each school, I believe they are the best data one can get without resorting to a cumbersome mobilization of academic bureaucracy, with the full panoply of lengthy questionnaires, protracted arguments about definitions, and other such delights.

The third possibility, i.e., that the general concem about physicians' use of drugs may be an exaggerated concern is, I believe, untenable and I mention it here only for the sake of completeness. The fact that many groups outside medical schools are interested in something would not of itself mean that their interest is justified. But the justification comes from the widespread use, importance, and power of modern drugs. The recent review of the efficacy and safety of a large number of drugs by a distinguished group of national committees has very clearly shown that physicians have available to them a broad series of potent compounds, for good and for ill. They also have available other drugs which, by their very popularity, suggest that their physician users should have been better instructed. Studies such as those of Dr. Leighton Cluff and his associates have thoroughly established the large number and variety of drugs administered to the usual hospital patient. (I do not suggest that increased knowledge of drugs would expand this use even further. On the contrary, increased teaching in this area would probably slim down the fat list of drugs presently prescribed, and this in itself would be no mean accomplishment.) Interaction among drugs has moved from laboratory theory to ward and outpatient fact. And the need for additional teaching in clinical pharmacology is supported by important examining bodies. For example, a review of the 51 self-assessment questions for internists published in the highly reputable Annals of Internal Medicine over a 12 month period from September, 1968, to August, 1969, shows that approximately 40 per cent of the questions were concerned, wholly or in part, with therapeutic or adverse effects of drugs; 25 per cent of the entire list were questions that involved drugs as their primary concern.

Finally, the ability of medical students 
to learn many things that are not given during formal class hours is, Deo gratias, an important consideration. Students can be, and doubtless often are, stimulated to make their own synthesis of information obtained in basic pharmacology courses and practical experience obtained during clinical clerkships with the use of such methods as additional reading, off-hour discussions, etc. The ability of some students to survive bad teaching practices in medical schools has often been noted. But it is no excuse for the continuation of such practices. Also, of course, there are many excellent clinical pharmacologists in institutions other than schools of medicine. The National Institutes of Health provide outstanding examples, and the pharmaceutical industry has its share. But medical schools and medical schools alone provide the primary training of physicians. Whenever medical schools fail to teach their students important principles and facts in some area of medicine, this information does not get imprinted into the primary mental matrix of the developing physician. Subsequent teaching can do much; indeed, I have used the existence of postgraduate teaching programs as one point in favor of certain medical schools in the opening paragraphs of this commentary. But the importance of postdoctoral training does not cancel out the principle under discussion now. If one wishes to assure that all physicians receive thorough grounding in some important area, that area must be taught extensively in medical schools.

While preparing this commentary, I took part in the oral examination of three senior medical students who had just completed a clinical period. They had been assigned to me at random for oral examination. It is important to note here that we have for many years been very fortunate in getting medical students of high intellectual caliber at the University of Michigan, as have many other medical schools, and at least two of the three students examined seemed basically to be rather bright people. Yet, among the three students examined, the following ideas were unearthed by questioning: A daily dose of 10,000 units of penicillin is the indicated dose in the treatment of pneumonia caused by a grampositive organism (admittedly, this just might work against the pneumococcus, but I doubt that anyone would recommend it as the usual regimen ); streptomycin given alone was mentioned as a reasonable treatment for subacute bacterial endocarditis caused by Streptococcus viridans, a suggestion that possibly derived from the poetic lilt of "streptomycin for streptococcus"; sulfonamides are a common cause of the nephrotic syndrome; it is incorrect to use a loading dose when digitalizing a patient. In addition to this torrent of misinformation, one student was aware that "thorazine" is a tranquilizing agent but could not even name the class of drug to which this agent belongs. One did not know that colchicine frequently causes diarrhea as a major adverse effect (heaven help his first gouty patient as the dosage mounts). Finally, whereas one of the three was confused about the proper method of digitalizing a patient, the other two (senior medical students, mind you) had no idea whatsoever about the digitalization of a patient and did not even attempt to answer that question. Again, let me stress that these were not three flunkers undergoing make-up examination but three students assigned at random during oral examination period, drawn from a class of individuals who are fundamentally bright people.

As I reflect on this dismal experience, certain points come to mind. First, there is little consolation in the fact that many of the questions happened to involve areas for which I do not have personal teaching responsibility. The time devoted to the teaching of clinical pharmacology and therapeutics is so brief that I would hesitate to suggest any better results if the students had been questioned about areas for which I do have more teaching responsibility. Second, it seems likely that 
the present situation is often underreported because of an easily understandable reluctance on the part of those who are aware of it; the first reaction of others may be the same as my first reaction, to be almost ashamed to report the facts. Third, the needlessness of the present situation is particularly frustrating. Virtually everyone who enters the area of clinical pharmacology does so because of strong interest in teaching as well as research. Moreover, a school is very unlikely to get a clinical pharmacology program unless the clinical pharmacologist has the support of his dean, the chairman of the department of pharmacology, and the chairman of a major clinical department (most often, internal medicine). These influential men must have decided to promote a clinical pharmacology program in their schools and must have accepted the credentials of their clinical pharmacology staff, after close scrutiny, or there would be no such program in existence in their schools. Admittedly, some programs began with the enthusiastic support of two of the three major individuals mentioned above, but most of us have had the good fortune to have all three supporting us or we would not have been able to begin. The reflex tendency to blame the higher echelons of medical education, deans and department chairmen, for the problem discussed here is probably in error; the opposition to improved teaching of clinical pharmacology and therapeutics probably comes from the middle echelon of academe. When battles are being lost, the top generals are usually more than willing to consider changes in strategy. The difficulty comes in getting top sergeants to change their ways. As for the teaching qualifications of the clinical pharmacologists in the various schools, the recent expansion in the number of these programs seems to me to have in no way diluted the quality of the programs. The teachers who have begun clinical pharmacology programs in the last few years have had better training and better qualifications than I had when I began a clinical pharmacology program.

As to the students, I do not believe that I am being naive in saying that we still attract a goodly number of students who enter medical schools with high motivation as well as appropriate intellectual qualifications. For I also had a session with the entire second year pharmacology class, early in their course, during the time of preparation of this commentary. This session was quite informal, with many questions from the student audience. The questions were almost uniformly of high caliber, reflecting a surprising amount of maturity, thoughtfulness, and good sense. Medical schools may yet fall into decay by attracting the type of student who comes to school to riot and grab power, and it will then be hopeless to try to teach anything to such students; but we cannot invoke this excuse for the teaching failure that has occurred thus far.

What about the regular staff members who are in charge of teaching basic pharmacology? They are in some instances friendly and in some instances cool toward the teaching of clinical pharmacology, but they are beset by their own troubles, in any event. For some schools have taken the surrealist position that the appropriate response to a need for more teaching about drugs is to gut their own pharmacology departments. If this move succeeds, it will usher in a new Ice Age in drug therapy, and God only knows what a bleak moraine will be left at its end.

Finally, any curriculum reform that consists in mere swapping of instruction hours between one year of medical school and another, in an atmosphere of academic horsetrading, will solve very little.

How far, then, has academe really risen to meet the challenge posed by advances in pharmacology and therapeutics? Apparently, it has risen about one Angstrom unit. 